\title{
Ventricular catheter entry site and not catheter tip location predicts shunt survival: a secondary analysis of $\mathbf{3}$ large pediatric hydrocephalus studies
}

\author{
William E. Whitehead, MD, ${ }^{1}$ Jay Riva-Cambrin, MD, MSc, ${ }^{2}$ Abhaya V. Kulkarni, MD, PhD, ${ }^{3}$ \\ John C. Wellons III, MD, MSPH, ${ }^{4}$ Curtis J. Rozzelle, MD, ${ }^{5}$ Mandeep S. Tamber, MD, PhD, ${ }^{6}$ \\ David D. Limbrick Jr., MD, PhD, ${ }^{7}$ Samuel R. Browd, MD, PhD, ${ }^{8}$ Robert P. Naftel, MD, ${ }^{4}$ \\ Chevis N. Shannon, MBA, MPH, DrPH, ${ }^{4}$ Tamara D. Simon, MD, MSPH, ${ }^{9}$ Richard Holubkov, PhD, ${ }^{10}$ \\ Anna IIIner, MD, ${ }^{11}$ D. Douglas Cochrane, MD, ${ }^{3}$ James M. Drake, FRCSC, ${ }^{3}$ \\ Thomas G. Luerssen, MD, ${ }^{1}$ W. Jerry Oakes, MD, ${ }^{5}$ and John R. W. Kestle, MD, ${ }^{12}$ for the \\ Hydrocephalus Clinical Research Network
}

'Department of Neurosurgery, Baylor College of Medicine, Houston, Texas; '2Division of Neurosurgery, University of Calgary, Alberta, Canada; ${ }^{3}$ Division of Neurosurgery, University of Toronto, Ontario, Canada; ${ }^{4}$ Department of Neurosurgery, Vanderbilt University, Nashville, Tennessee; ${ }^{5}$ Department of Neurosurgery, University of Alabama at Birmingham, Alabama; ${ }^{6}$ Department of Neurosurgery, University of Pittsburgh, Pennsylvania; 'Department of Neurosurgery, Washington University, St. Louis, Missouri; Departments of ${ }^{8}$ Neurosurgery and ${ }^{9}$ Pediatrics, University of Washington, Seattle, Washington; ${ }^{10}$ Department of Pediatrics, University of Utah, Salt Lake City, Utah; ${ }^{11}$ Department of Radiology, Baylor College of Medicine, Houston, Texas; and ${ }^{12}$ Department of Neurosurgery, University of Utah, Salt Lake City, Utah

OBJECTIVE Accurate placement of ventricular catheters may result in prolonged shunt survival, but the best target for the hole-bearing segment of the catheter has not been rigorously defined. The goal of the study was to define a target within the ventricle with the lowest risk of shunt failure.

METHODS Five catheter placement variables (ventricular catheter tip location, ventricular catheter tip environment, relationship to choroid plexus, catheter tip holes within ventricle, and crosses midline) were defined, assessed for interobserver agreement, and evaluated for their effect on shunt survival in univariate and multivariate analyses. De-identified subjects from the Shunt Design Trial, the Endoscopic Shunt Insertion Trial, and a Hydrocephalus Clinical Research Network study on ultrasound-guided catheter placement were combined ( $n=858$ subjects, all first-time shunt insertions, all patients $<18$ years old). The first postoperative brain imaging study was used to determine ventricular catheter placement for each of the catheter placement variables.

RESULTS Ventricular catheter tip location, environment, catheter tip holes within the ventricle, and crosses midline all achieved sufficient interobserver agreement $(\kappa>0.60)$. In the univariate survival analysis, however, only ventricular catheter tip location was useful in distinguishing a target within the ventricle with a survival advantage (frontal horn; log-rank, $p=0.0015)$. None of the other catheter placement variables yielded a significant survival advantage unless they were compared with catheter tips completely not in the ventricle. Cox regression analysis was performed, examining ventricular catheter tip location with age, etiology, surgeon, decade of surgery, and catheter entry site (anterior vs posterior). Only age $(p<0.001)$ and entry site $(p=0.005)$ were associated with shunt survival; ventricular catheter tip location was not $(p=0.37)$. Anterior entry site lowered the risk of shunt failure compared with posterior entry site by approximately one-third (HR 0.65, 95\% Cl 0.51-0.83).

CONCLUSIONS This analysis failed to identify an ideal target within the ventricle for the ventricular catheter tip. Unexpectedly, the choice of an anterior versus posterior catheter entry site was more important in determining shunt survival

ABBREVIATIONS ESIT = Endoscopic Shunt Insertion Trial; HCRN = Hydrocephalus Clinical Research Network; IVH = intraventricular hemorrhage; SDT = Shunt Design

Trial.

SUBMITTED April 25, 2016. ACCEPTED August 18, 2016.

INCLUDE WHEN CITING Published online November 4, 2016; DOI: 10.3171/2016.8.PEDS16229. 
than the location of the ventricular catheter tip within the ventricle. Entry site may represent a modifiable risk factor for shunt failure, but, due to inherent limitations in study design and previous clinical research on entry site, a randomized controlled trial is necessary before treatment recommendations can be made.

http://thejns.org/doi/abs/10.3171/2016.8.PEDS16229

KEY WORDS hydrocephalus; pediatric; CSF shunts; shunt entry site; ventricular catheter

$\mathrm{T}$ HE concept that there is an ideal location within the ventricles for the hole-bearing segment of the ventricular catheter has been mentioned in the literature for many years. ${ }^{2,9}$ There is clinical evidence suggesting that ventricular catheter tips in certain locations (e.g., the frontal horn, the occipital horn, away from the choroid plexus) have longer survival than catheters in other locations..$^{5,9,10}$ However, these targets have never been rigorously defined and validated, and uncertainty exists over where the best target is located.

In the present study, we attempt to rigorously define targets for CSF ventricular catheter tips, evaluate their effect on shunt survival, and define the best target based on time to shunt failure. To do this, we performed a secondary analysis of 3 previous pediatric hydrocephalus studies. We hypothesized that catheter placement in the frontal horn away from the choroid plexus and surrounded by CSF would be an independent predictor of longer shunt survival.

\section{Methods}

The institutional review board at Baylor College of Medicine approved this study. De-identified data from the Shunt Design Trial (SDT), ${ }^{4}$ the Endoscopic Shunt Insertion Trial (ESIT), ${ }^{5}$ and a study on ventricular catheter insertion with and without ultrasound by the Hydrocephalus Clinical Research Network (HCRN) ${ }^{11}$ were combined. All 3 studies, which collectively recruited patients between 1993 and 2010, used similar eligibility criteria (e.g., all first-time ventriculoperitoneal shunt insertions and all subjects $<18$ years old) and the same definition for shunt failure. Shunt failure was divided into 4 categories: obstruction, overdrainage, loculations, and infection. Each category was objectively defined based on clinical symptoms, signs, radiographic findings, and ancillary test results; if a subject met criteria for any of the 4 categories, shunt failure was said to have occurred.

\section{Defining Ventricular Catheter Placement}

Variables that describe the placement of ventricular catheter tips were obtained from the literature and were created by consensus agreement among the HCRN investigators. Explicit definitions for these placement variables were developed in collaboration with a pediatric neuroradiologist and are listed below. The catheter tip, or the hole-bearing segment of the catheter, was defined as the most proximal $2 \mathrm{~cm}$.

Ventricular catheter tip location ${ }^{11}$ was determined by one of the following 8 compartments: frontal horn, trigone, body, temporal horn, third ventricle, fourth ventricle, cistern, or brain. If the catheter tip penetrated the ependyma or pia ( $\geq 3 \mathrm{~mm}$ ) and was in the brain or cistern, the catheter was scored as such, regardless of the depth of tissue or cistern penetration. If the catheter tip was entirely intraventricular but crossed the boundary between 2 compartments, the compartment with the majority of the catheter tip was selected. The boundary between the frontal horn and body was defined as a coronal plane through the foramen of Monro and the anterior border of the thalamus; likewise, the border between the body and trigone was a coronal plane at the posterior border of the thalamus.

Ventricular catheter tip environment ${ }^{10}$ was defined by one of the following 4 environments: tip surrounded completely by CSF, tip touching the ventricular wall, tip penetrating the ventricular wall $(\geq 3 \mathrm{~mm}$, but $<2 \mathrm{~cm}$ ), and tip completely not in the ventricle $(\geq 2 \mathrm{~cm}$ of the proximal tip in the brain/cistern).

Relationship to choroid plexus ${ }^{5}$ was divided into catheter tips touching the choroid plexus, tips not touching the choroid plexus, and tips completely not in the ventricle $(\geq$ $2 \mathrm{~cm}$ of the proximal tip in the brain/cistern).

Catheter tip holes within the ventricle were divided into 4 categories: all catheter tip holes within the ventricle, catheter too long (i.e., holes closest to tip not in the ventricle), catheter too short (i.e., holes farthest from tip not in the ventricle), and catheter not in the ventricle (i.e., all holes in the brain/cistern).

Crosses midline was divided into 3 categories: the majority of the catheter tip does not cross midline, the majority of the catheter tip does cross midline, and catheter is not in the ventricle $(\geq 2 \mathrm{~cm}$ of proximal tip in the brain/ cistern).

\section{Reliability Testing of Catheter Placement Variables}

To assess reliability of the placement variables, 2 independent observers (a neuroradiologist and a neurosurgeon) reviewed the 121 imaging studies from the HCRN study on ventricular catheter insertion and determined the catheter tip position for each variable. Interobserver agreement was measured using the Kappa statistic.

\section{Defining the Best Target for Catheter Placement Based on Time to Shunt Failure}

The catheter placement variables with adequate interobserver agreement $(\kappa>0.60)$ were then collected for all subjects using the first postoperative image. Shunt survival curves were generated for each placement variable and were compared to determine the best targets. Placement variables showing a statistically significant survival advantage were evaluated in a multivariate Cox proportional hazard regression model with other variables known or suspected to affect shunt survival (age $[<1$ month, 1 month to $<6$ months, 6 months to $<12$ months, 12 months to 10 years; $>10$ years], surgeon, etiology of 

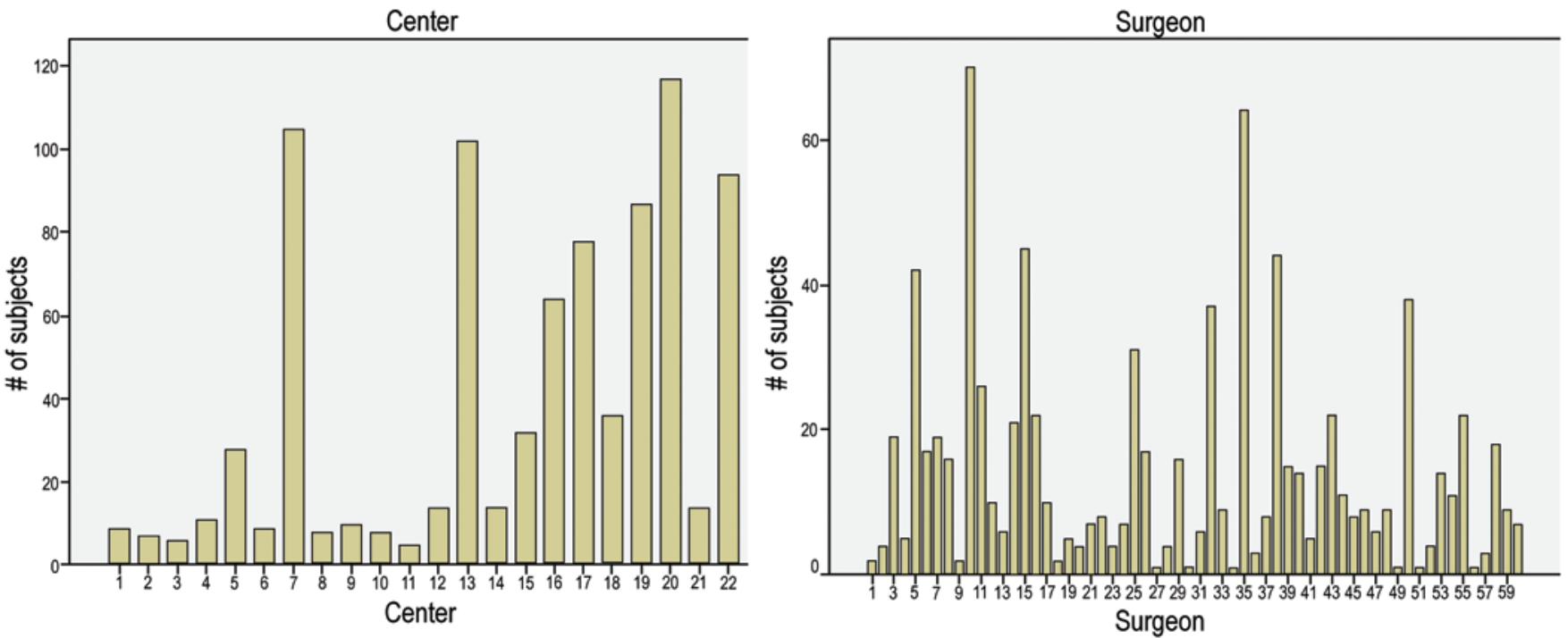

FIG. 1. Bar charts showing the number of subjects treated from each center (left) and surgeon (right). Figure is available in color online only.

hydrocephalus [aqueductal stenosis, brain tumor, intraventricular hemorrhage (IVH) of prematurity, myelomeningocele, head injury, CSF infection, 2 etiologies indicated, other, unknown], decade of shunt insertion [1990s, 2000s], and catheter entry site [anterior, posterior]).

\section{Data Analysis}

Descriptive statistics were used to report baseline characteristics of the cohort. The degree of interobserver agreement was assessed using the kappa statistic for dichotomous or unordered categorical factors. A $\kappa$ score of $>0.60$ was selected as the lower limit for sufficient reliability. ${ }^{8}$ The sample size for determining interobserver agreement was based on the number of variables being evaluated, with a goal of at least 10 subjects per variable analyzed.

Reliable placement variables were evaluated for association with shunt failure in univariate models. Survival curves were calculated using the Kaplan-Meier method. For the survival analysis, date of shunt failure, or date that the patient was last known to be alive with a patent shunt was used. The log-rank test was used to make an overall comparison of survival distributions, and then pairwise comparisons were made between variable subcategories to define the best placement based on shunt survival curves (e.g., for the variable ventricular catheter tip location, a pairwise comparison was made between the frontal horn and body placements, and then another comparison between the frontal horn and trigone). Univariate analysis was also performed to assess the effect of age, etiology, decade of shunt insertion, and catheter entry site on shunt survival within the cohort. Surgeon was included as a random effect in the survival model to account for possible clustering within patients treated by the same surgeon. While $p$ values are reported for the significance of this effect, the final models account for this clustering regardless of significance. Model results without controlling for surgeon were very similar to those reported.
Factors were selected for entry into a multivariable Cox model if they were found to be significant $(\mathrm{p}<0.05)$ or nearly significant $(\mathrm{p}<0.10)$ on univariate analysis. Cox regression was used to determine which variables were independently associated with shunt survival. Adequacy of the proportional hazards assumption was tested by modeling association between predictors in the model and survival time; an assessment of this association was nonsignificant $(\mathrm{p}=0.88)$ in the final reported model.

\section{Results}

\section{Baseline Characteristics}

The combined cohort from the 3 studies contained 858 subjects. In total, 22 centers and 60 surgeons contributed subjects (Fig. 1). The center with the most subjects comprised $13.6 \%$ of the data set (mean number of subjects/ center 39, SD 39.4, median 14, minimum 5, maximum 117). The surgeon with the most subjects made up $8.2 \%$ of the data set (mean number of subjects/surgeon 14.3, SD 14.9, median 9, minimum 1, maximum 70). Baseline characteristics of the combined cohort are shown in Table 1 . Overall, the population is a heterogeneous sample from large American (15), Canadian (3), and European (4) centers. There were 655 reviewable postoperative images for analysis. Thirteen subjects were lost to follow-up within 1 year of surgery; otherwise, all subjects were monitored for at least 1 year or until they met criteria for shunt failure.

\section{Determining Interobserver Agreement for Catheter Placement Variables}

Interobserver agreement results are shown in Table 2. Variables with sufficient agreement $(\kappa>0.6)$ were ventricular catheter tip location, ventricular catheter tip environment, catheter tip holes within the ventricle, and crosses midline. Poor interobserver agreement was seen for relationship to the choroid plexus, and therefore this variable was excluded from further analysis. 
TABLE 1. Baseline characteristics

\begin{tabular}{|c|c|c|c|c|}
\hline Variable & $\begin{array}{c}\text { SDT } \\
(n=344)\end{array}$ & $\begin{array}{c}\text { ESIT } \\
(n=393)\end{array}$ & $\begin{array}{l}\text { HCRN Ultrasound } \\
\text { Study }(n=121)\end{array}$ & $\begin{array}{l}\text { Combined Cohort } \\
\qquad(n=858)\end{array}$ \\
\hline Dates of enrollment & 1993-1995 & 1996-1999 & 2009-2010 & 1993-2010 \\
\hline Mean age $\pm S D$, yrs & $1.54 \pm 3.30$ & $1.70 \pm 3.68$ & $1.11 \pm 2.46$ & $1.55 \pm 3.38$ \\
\hline \multicolumn{5}{|l|}{ Categorical age } \\
\hline$<1 \mathrm{mo}$ & $107(31.1 \%)$ & $132(33.6 \%)$ & $41(33.9 \%)$ & $280(32.6 \%)$ \\
\hline 1 to $<6$ mos & $127(36.9 \%)$ & $120(30.5 \%)$ & $44(36.4 \%)$ & $291(33.9 \%)$ \\
\hline 6 to $<12$ mos & $32(9.3 \%)$ & $50(12.7 \%)$ & $13(10.7 \%)$ & $95(11.1 \%)$ \\
\hline 1 to $<10$ mos & $60(17.4 \%)$ & $66(16.8 \%)$ & $20(16.5 \%)$ & $146(17.0 \%)$ \\
\hline$\geq 10$ yrs & $18(5.2 \%)$ & $25(6.4 \%)$ & $3(2.5 \%)$ & $46(5.4 \%)$ \\
\hline Female sex & $153(44.5 \%)$ & $178(45.3 \%)$ & $44(36.4 \%)$ & $375(43.7 \%)$ \\
\hline \multicolumn{5}{|l|}{ Etiology } \\
\hline Aqueductal stenosis & $24(7.0 \%)$ & $29(7.4 \%)$ & $8(6.6 \%)$ & $61(7.1 \%)$ \\
\hline Brain tumor & $31(9.0 \%)$ & $19(4.8 \%)$ & $13(10.7 \%)$ & $63(7.3 \%)$ \\
\hline IVH of prematurity & $83(24.1 \%)$ & $82(20.9 \%)$ & $41(33.9 \%)$ & $206(24.0 \%)$ \\
\hline Myelomeningocele & $73(21.2 \%)$ & $108(27.5 \%)$ & $33(27.3 \%)$ & $214(24.9 \%)$ \\
\hline Head injury & $5(1.5 \%)$ & $13(3.3 \%)$ & $1(0.8 \%)$ & $19(2.2 \%)$ \\
\hline CSF infection & $18(5.2 \%)$ & $16(4.1 \%)$ & $2(1.7 \%)$ & $36(4.2 \%)$ \\
\hline 2 indicated & $30(8.7 \%)$ & $17(4.3 \%)$ & 0 & $47(5.5 \%)$ \\
\hline Other & $39(11.3 \%)$ & $27(6.9 \%)$ & $23(19.0 \%)$ & $89(10.4 \%)$ \\
\hline Unknown & $38(11.0 \%)$ & $82(20.9 \%)$ & 0 & $120(14.0 \%)$ \\
\hline Missing data & $3(0.9 \%)$ & 0 & 0 & $3(0.3 \%)$ \\
\hline \multicolumn{5}{|l|}{ Entry site } \\
\hline Anterior & $54(15.7 \%)$ & $170(43.3 \%)$ & $75(62.0 \%)$ & $299(34.8 \%)$ \\
\hline Posterior & $290(84.3 \%)$ & $216(55.0 \%)$ & $46(38.0 \%)$ & $552(64.3 \%)$ \\
\hline Missing data & 0 & $7(1.8 \%)$ & 0 & $7(0.8 \%)$ \\
\hline No. of surgeons & 29 & 34 & 17 & 60 \\
\hline No. of centers & 12 & 16 & 4 & 22 \\
\hline \multicolumn{5}{|l|}{ Postop images } \\
\hline Available \& adequate & $256(74.4 \%)$ & $282(71.8 \%)$ & $117(96.7 \%)$ & $655(76.3 \%)$ \\
\hline No image & $53(15.4 \%)$ & $83(21.1 \%)$ & $2(1.7 \%)$ & $138(16.1 \%)$ \\
\hline Inadequate to determine catheter position & $35(10.2 \%)$ & $28(7.1 \%)$ & $2(1.7 \%)$ & $65(7.6 \%)$ \\
\hline \multicolumn{5}{|l|}{ Postop day of scan } \\
\hline Mean \pm SD & $115 \pm 120$ & $118 \pm 133$ & $32 \pm 74$ & $101 \pm 123$ \\
\hline Median & 91 & 90 & 1 & 83 \\
\hline Mode & 90 & 1 & 1 & 1 \\
\hline Range & $0-1091$ & $0-958$ & $0-367$ & $0-1091$ \\
\hline
\end{tabular}

\section{Defining the Best Target for Catheter Tip Placement Based on Time to Shunt Failure}

The catheter tip placement variables with sufficient interobserver agreement were then collected for the entire cohort by a single observer, blinded to outcome, using the first postoperative scan. Kaplan-Meier survival curves were generated for each variable. These results are shown in Fig. 2. The first variable, ventricular catheter tip location (Fig. 2A), showed a significant difference in survival among locations with frontal horn showing the best survival (overall comparison; log-rank, $p=0.0015$ ). When pairwise comparisons were made between curves, frontal horn catheters showed a significant survival advantage compared with catheters in the body of the lateral ventricle and catheters in the brain (log-rank, $\mathrm{p}<0.05$ ). There was not a significant difference in survival between catheters in the frontal horn and catheters in the trigone (log-rank, $\mathrm{p}=0.17)$. Catheters in the cistern $(\mathrm{n}=5)$, third ventricle $(n=9)$, and temporal horn $(n=6)$ were removed from the analysis due to low numbers $(<10)$.

In the overall comparison for the second placement variable, ventricular catheter tip environment (Fig. 2B), the differences in shunt survival approached statistical significance (overall comparison; log-rank, $\mathrm{p}=0.058$ ). However, when pairwise comparisons were made between groups, there was no significant difference in survival among catheters surrounded by CSF, touching ventricular walls, or penetrating ventricular walls. The only significant dif- 
TABLE 2. Interobserver agreement for catheter position variables*

\begin{tabular}{lcc}
\hline \multicolumn{1}{c}{ Variable } & Kappa & $95 \% \mathrm{Cl}$ \\
\hline Ventricular catheter tip location & $\mathbf{0 . 7 2}$ & $\mathbf{0 . 6 2 - 0 . 8 3}$ \\
\hline Ventricular catheter tip environment & $\mathbf{0 . 8 1}$ & $\mathbf{0 . 7 0 - 0 . 9 1}$ \\
\hline Relationship to choroid plexus & 0.56 & $0.40-0.71$ \\
\hline Holes in ventricle & $\mathbf{0 . 7 4}$ & $\mathbf{0 . 5 5 - 0 . 9 3}$ \\
\hline Crosses midline & $\mathbf{0 . 9 2}$ & $\mathbf{0 . 8 3 - 1 . 0 0}$ \\
\hline
\end{tabular}

Boldface type indicates sufficient agreement $(>0.60)$.

* Two independent observers.

ference between groups occurred in the comparison of catheters touching ventricular wall and not in the ventricle (log-rank, $p=0.015)$. Because this variable failed to yield a significant difference between possible desirable targets within the ventricle and only showed that a subset of catheters in the ventricle survive longer than catheters in the brain, it was excluded from further analysis.

Catheter tip holes within the ventricle (Fig. 2C) showed a significant difference in the overall comparison among its 4 strata (log-rank, $\mathrm{p}=0.031$ ), but in the pairwise comparisons between groups, significant differences in survival were only seen when a comparison was made to catheters not in ventricle. There was no significant difference in survival in pairwise comparisons between all holes in ventricle, catheter too long (some of the holes closest to the tip in the brain), and catheter too short (some of the holes farthest from the tip in the brain). The analysis of this variable was also not successful in defining an intraventricular target for the catheter, and thus it was also excluded from further analysis.

The univariate analysis for catheters crossing midline (Fig. 2D) showed no significant difference in shunt survival in the overall comparison of its 3 strata (log-rank, $\mathrm{p}=0.142$ ). Pairwise comparisons showed no significant differences in survival between catheters that cross midline and catheters that do not cross midline. This variable, therefore, was also excluded from any additional analysis.

Other variables with known or possible effects on shunt survival (i.e., age, etiology, surgeon, decade of surgery, and entry site) were independently analyzed to measure their effect on shunt survival in this cohort. Age (log-rank, $\mathrm{p}<0.001$ ), etiology (log-rank, $\mathrm{p}=0.068$ ), and entry site (log-rank, $\mathrm{p}<0.001)$ all had a significant or near-significant effect on shunt survival and were included in the multivariate analysis to examine association with shunt survival. The effect of entry site on survival was greater than expected; the survival curves for entry site are shown in Fig. 3.

To complete the planned analysis, a Cox regression model was performed with the variables ventricular catheter tip location, age, etiology, decade of surgery, and entry site. Within-surgeon clustering of outcomes was modeled using a random effect in all models. The results of the initial model and final model are shown in Table 3. When all variables were adjusted for, ventricular catheter tip location had no significant effect on shunt survival. Entry site, however, did show a significant effect on survival after adjusting for the effects of age, etiology, and surgeon. As ventricular catheter tip location and decade of surgery did not exhibit trends $(\mathrm{p}>0.10)$ for association with outcome in a stepwise multivariable model, these factors were not included in the final model. The final model suggests that entry site is a significant factor in determining shunt survival and ventricular catheter tip location is not. Anterior entry site lowered the risk of shunt failure by approximately one-third compared with posterior entry (HR 0.648, 95\% CI 0.505-0.831).

\section{Post Hoc Analyses}

Because these results challenged our initial hypothesis (that catheters in the frontal horn away from the choroid plexus and surrounded by CSF have the longest survival regardless of entry site), we performed additional, unplanned analyses to better characterize the effect and understand the results. Table 4 compares baseline characteristics between anterior and posterior entry sites. There are significant differences between the 2 groups for age, decade of shunt insertion, and surgeon experience. The posterior group contains a higher percentage of younger subjects, a lower percentage of subjects treated recently (2009-2010), and a lower percentage of surgeons contributing 10 or more subjects to the data set (a surrogate variable for experience). All of these imbalances favor the anterior entry site group. The multivariate proportional hazard regression model takes these into account and attempts to adjust for these differences.

We investigated the possibility that entry site acts as a confounder on the relationship between ventricular catheter tip location and shunt survival. To act as a confounder, a variable must be associated with both the risk factor of interest (ventricular catheter tip location) and the outcome (time to shunt failure), it must be distributed unequally among the groups being compared, and it cannot be an intermediary step in the causal pathway from exposure of interest to outcome. ${ }^{7}$ All of these conditions are met. First, we have shown that entry site selection is associated with the outcome time to shunt failure (Fig. 3). We can also show that there is an association between choice of entry site and ventricular catheter tip location; these associations are shown in Table 5 under the subheading "Column \%." For example, catheters placed from an anterior approach have a much higher likelihood of placement in the frontal horn than catheters from a posterior approach $(75.6 \%$ vs $23.7 \%$ ). It is also true that posterior entry catheters are more likely to be in the trigone than anterior entry catheters (26.7\% vs $0.4 \%$ ). Second, Table 5 also confirms that there is an unequal distribution of entry sites among the ventricular catheter tip locations being compared in this cohort (see Table 5, "Row \%"). For example, most catheters in the frontal horn are from an anterior entry site rather than a posterior entry site (67.5\% vs $32.5 \%$, respectively). Finally, entry site selection is modifiable; it is a choice made by the surgeon. It cannot be considered an intermediary step in the causal pathway from shunt insertion to shunt failure.

Contrary to our hypothesis, the results suggest that catheters in the frontal horn from an anterior entry site survive longer than catheters in the frontal horn from a posterior entry site. For clarity, a comparison of shunt survival curves for these 2 situations was performed and is 
A Shunt Survival Curves for Ventricular Catheter Location

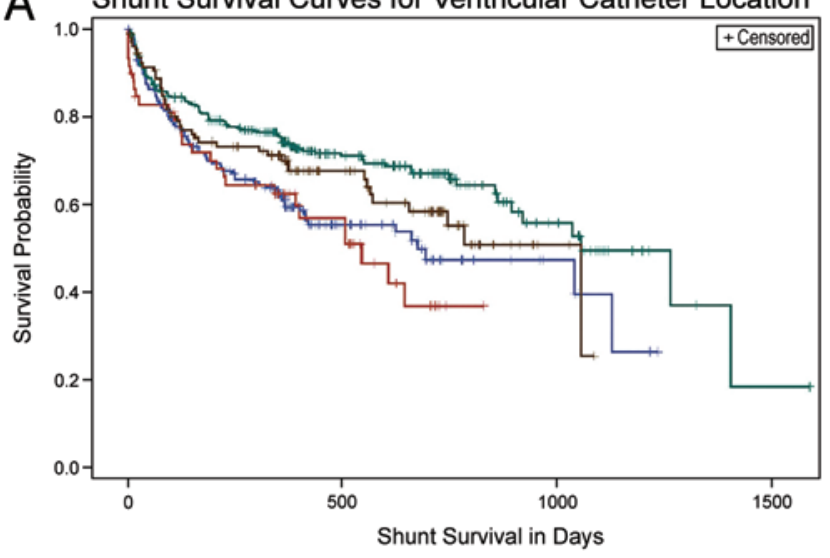

\begin{tabular}{|c|c|c|c|c|c|c|c|c|}
\hline \multirow{3}{*}{$\begin{array}{l}\text { Ventricular } \\
\text { Catheter Location }\end{array}$} & \multicolumn{8}{|c|}{$\begin{array}{l}\text { Ventricular Catheter Location } \\
\text { Brain } \\
\text { Frontal Horn }\end{array}$} \\
\hline & \multicolumn{2}{|c|}{ Frontal Horn } & \multicolumn{2}{|c|}{ Trigone } & \multicolumn{2}{|l|}{ Body } & \multicolumn{2}{|l|}{ Brain } \\
\hline & $x^{2}$ & $P$ & $x^{2}$ & p & $\overline{x^{2}}$ & p & $x^{2}$ & $p$ \\
\hline Frontal Horn & & & 1.86 & 0.17 & 10.11 & 0.0015 & 9.94 & 0.002 \\
\hline Trigone & 1.86 & 0.17 & & & 1.52 & 0.22 & 3.15 & 0.08 \\
\hline Body & 10.11 & 0.0015 & 1.52 & 0.22 & & & 0.45 & 0.50 \\
\hline Brain & 9.94 & 0.002 & 3.15 & 0.08 & 0.45 & 0.50 & & \\
\hline
\end{tabular}

C

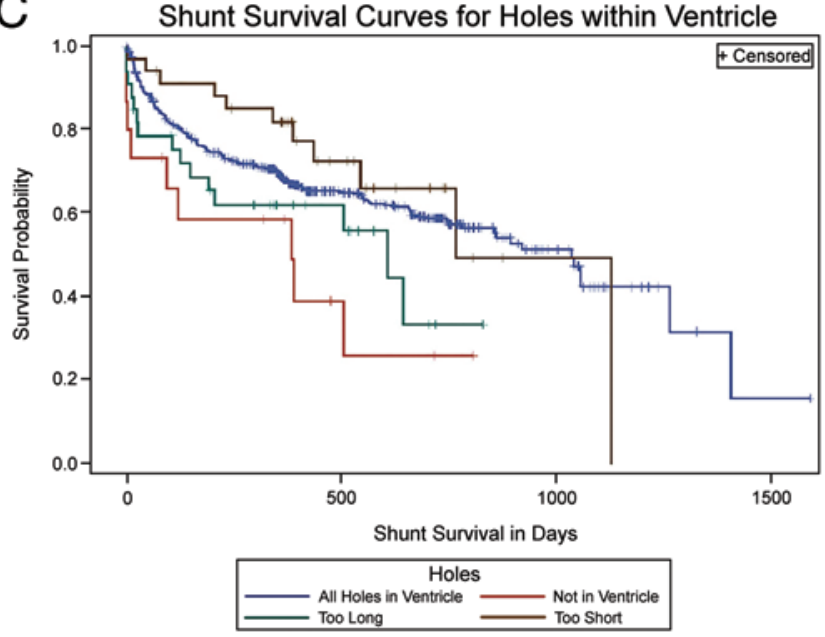

\begin{tabular}{|c|c|c|c|c|c|c|c|c|}
\hline \multirow[t]{2}{*}{$\begin{array}{l}\text { Catheter tip holes } \\
\text { within ventricle }\end{array}$} & \multicolumn{2}{|c|}{$\begin{array}{l}\text { All holes in } \\
\text { ventricle }\end{array}$} & \multicolumn{2}{|c|}{ Catheter too short } & \multicolumn{2}{|c|}{ Catheter too long } & \multicolumn{2}{|c|}{ Not in Ventricle } \\
\hline & $x^{2}$ & P & $x^{2}$ & $p$ & $x^{2}$ & $p$ & $X^{2}$ & $p$ \\
\hline $\begin{array}{l}\text { All holes in } \\
\text { ventricle }\end{array}$ & & & 0.56 & 0.45 & 2.66 & 0.103 & 5.56 & 0.018 \\
\hline Too Short & 0.56 & 0.45 & & & 3.59 & 0.058 & 6.07 & 0.014 \\
\hline Too Long & 2.66 & 0.103 & 3.59 & 0.058 & & & 0.91 & 0.34 \\
\hline Not in Ventricle & 5.56 & 0.018 & 6.07 & 0.014 & 0.91 & 0.34 & & \\
\hline
\end{tabular}

B Shunt Survival Curves for Ventricular Catheter Environment

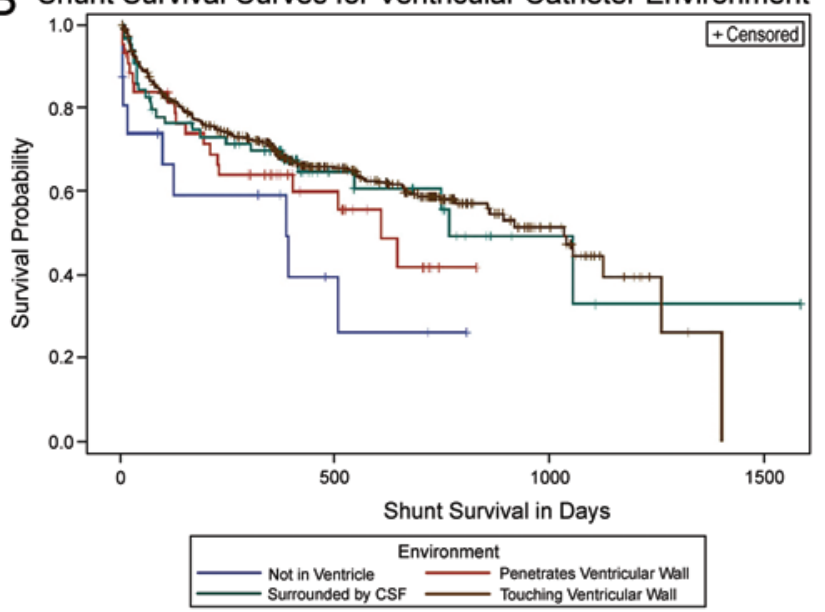

\begin{tabular}{|l|l|l|l|l|l|l|l|l|}
\hline $\begin{array}{l}\text { Ventricular } \\
\text { Catheter } \\
\text { Environment }\end{array}$ & \multicolumn{2}{l|}{$\begin{array}{l}\text { Surrounded by } \\
\text { CSF }\end{array}$} & \multicolumn{2}{l|}{ Touching Wall } & \multicolumn{2}{l|}{ Penetrating Wall } & \multicolumn{2}{l|}{ Not in Ventricle } \\
\cline { 2 - 9 } & $X^{2}$ & $p$ & $X^{2}$ & $p$ & $X^{2}$ & $p$ & $X^{2}$ & $p$ \\
\hline $\begin{array}{l}\text { Surrounded by } \\
\text { CSF }\end{array}$ & & & 0.08 & 0.77 & 0.84 & 0.36 & 3.43 & 0.06 \\
\hline Touching Wall & 0.08 & 0.77 & & & 2.01 & 0.16 & 5.93 & 0.015 \\
\hline Penetrating Wall & 0.84 & 0.36 & 2.01 & 0.16 & & & 1.61 & 0.20 \\
\hline Not in Ventricle & 3.43 & 0.06 & 5.63 & 0.015 & 1.61 & 0.20 & & \\
\hline
\end{tabular}

D

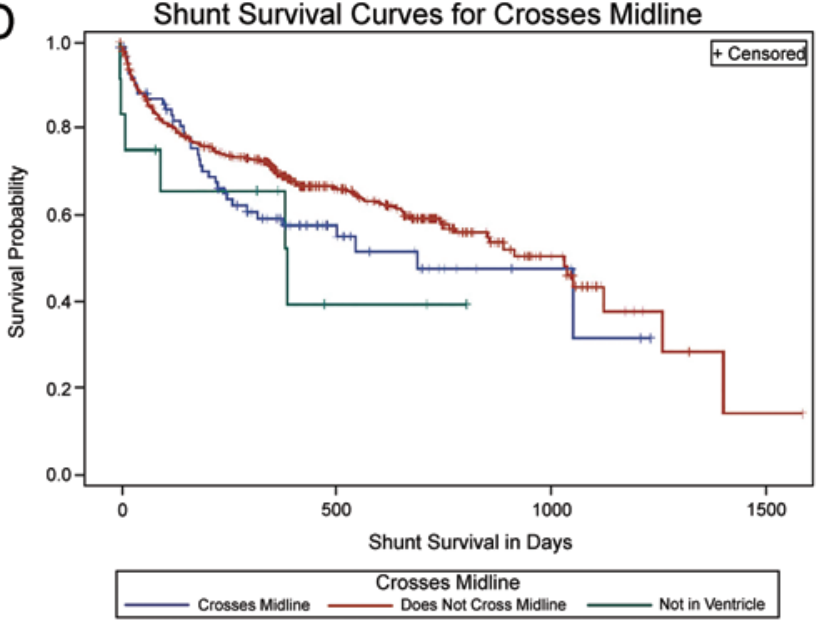

\begin{tabular}{|l|l|l|l|l|l|l|}
\hline Crosses midline & \multicolumn{2}{|l|}{$\begin{array}{l}\text { Does not cross } \\
\text { midline }\end{array}$} & \multicolumn{2}{l|}{ Crosses Midline } & \multicolumn{2}{l|}{ Not in Ventricle } \\
\cline { 2 - 7 } & $X^{2}$ & $p$ & $X^{2}$ & $p$ & $X^{2}$ & $p$ \\
\hline $\begin{array}{l}\text { Does not cross } \\
\text { midline }\end{array}$ & & & 2.18 & 0.14 & 2.00 & 0.16 \\
\hline Crosses Midline & 2.18 & 0.14 & & & 0.45 & 0.50 \\
\hline Not in Ventricle & 2.00 & 0.16 & 0.45 & 0.50 & & \\
\hline
\end{tabular}

FIG. 2. Kaplan-Meier shunt survival curves with pairwise comparison tables for between curve comparisons. Crosses on curves depict censored subject. Log-rank tests for significance for the overall comparison of survival distributions were as follows: ventricular catheter tip location, log-rank $\chi^{2}=15.434, p=0.0015(\mathbf{A})$; ventricular catheter tip environment, log-rank $\chi^{2}=7.486, p=0.058$ (B); catheter tip holes within ventricle, log-rank $\chi^{2}=8.875, p=0.031(C)$; crosses midline: log-rank $\chi^{2}=3.902, p=0.142$ (D). Tables below shunt survival curves show log-rank chi-square test result and $p$ values when 2 curves are compared with each other.

shown in Fig. 4; all catheter tips in this figure are in the frontal horn. The analysis shows a significant difference between the 2 entry sites with anterior entry site catheters surviving longer (log-rank, $\mathrm{p}=0.035)$.
Finally, we compared the subtypes of shunt failure (i.e., obstruction, overdrainage, loculation, and infection) between the 2 entry sites in Table 6 . The difference in shunt survival appears to be due to a significant difference in the 


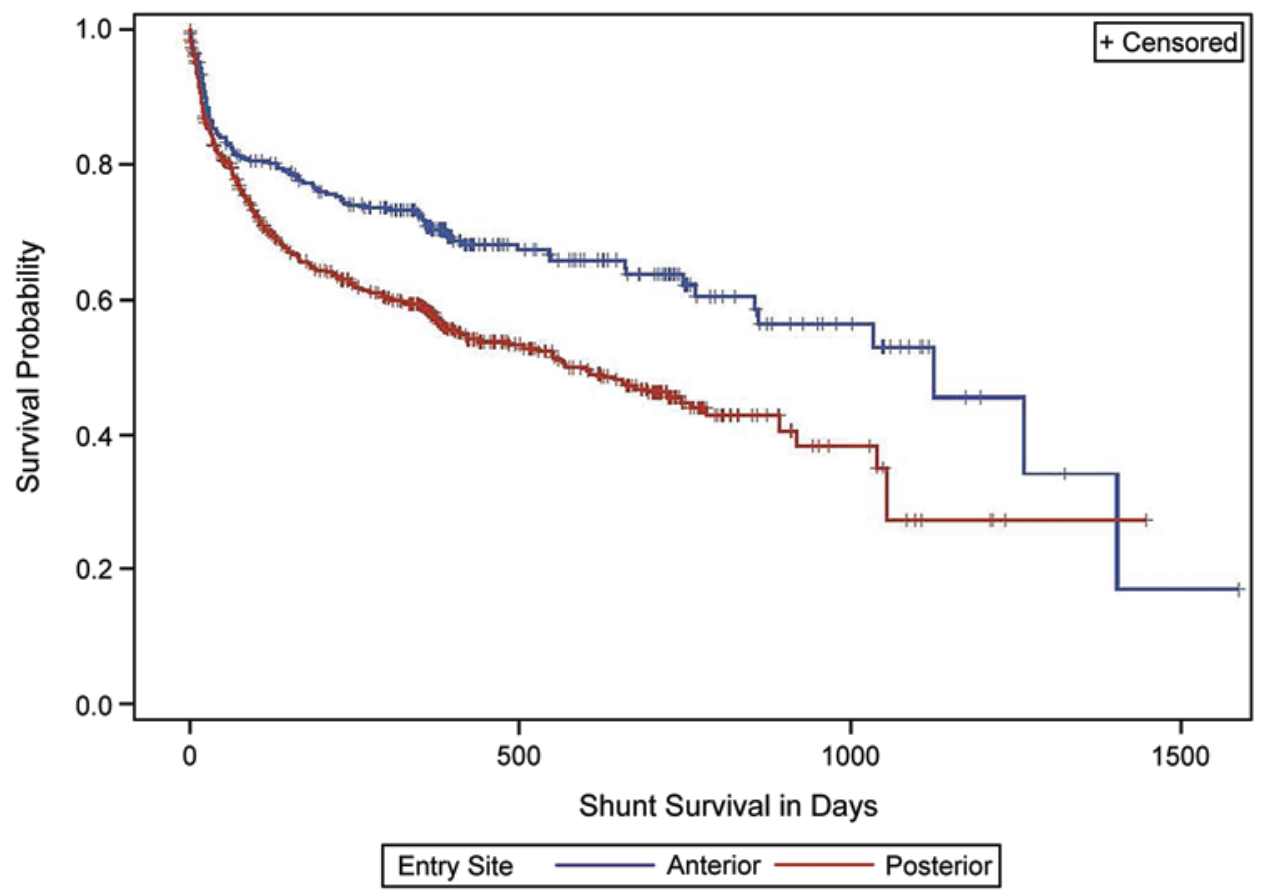

FIG. 3. Kaplan-Meier shunt survival curves for entry site. Log-rank $\chi^{2}=16.145, p<0.001$.

TABLE 3. Results of Cox proportional hazard model analysis

\begin{tabular}{|c|c|c|c|c|}
\hline \multirow[b]{2}{*}{ Variable } & \multicolumn{2}{|c|}{ Preliminary Model $(n=652)$} & \multicolumn{2}{|c|}{ Final Model $(n=848)$} \\
\hline & Adjusted HR (95\% Cl) & p Value & Adjusted HR (95\% Cl) & $\mathrm{p}$ Value \\
\hline Anterior entry site & $0.674(0.471-0.963)$ & 0.025 & $0.648(0.505-0.831)$ & 0.005 \\
\hline Age & & 0.002 & & $<0.001$ \\
\hline$<1 \mathrm{mo}$ & Referent & Referent & Referent & Referent \\
\hline 1 to $<6$ mos & $0.511(0.343-0.761)$ & 0.001 & $0.497(0.368-0.670)$ & $<0.001$ \\
\hline 6 to $<12 \mathrm{mos}$ & $0.448(0.265-0.758)$ & 0.003 & $0.409(0.267-0.625)$ & $<0.001$ \\
\hline 1 to $<10 \mathrm{yrs}$ & $0.435(0.257-0.734)$ & 0.002 & $0.409(0.268-0.624)$ & $<0.001$ \\
\hline$>10 \mathrm{yrs}$ & $0.628(0.318-1.240)$ & 0.181 & $0.499(0.278-0.895)$ & 0.02 \\
\hline Etiology & & 0.011 & & 0.16 \\
\hline Aqueductal stenosis & Referent & Referent & Referent & Referent \\
\hline Myelomeningocele & $0.928(0.529-1.628)$ & 0.80 & $0.958(0.611-1.503)$ & 0.85 \\
\hline IVH of prematurity & $1.132(0.654-1.960)$ & 0.66 & $1.287(0.821-2.019)$ & 0.27 \\
\hline Brain tumor & $1.608(0.769-3.364)$ & 0.21 & $1.323(0.691-2.534)$ & 0.40 \\
\hline CSF infection & $2.752(1.358-5.575)$ & 0.005 & $1.952(1.064-3.584)$ & 0.03 \\
\hline Head injury & $1.256(0.470-3.356)$ & 0.65 & $1.213(0.482-3.053)$ & 0.68 \\
\hline 2 indicated & $1.094(0.513-2.331)$ & 0.82 & $1.299(0.717-2.353)$ & 0.39 \\
\hline Other & $0.676(0.355-1.288)$ & 0.23 & $0.789(0.460-1.353)$ & 0.39 \\
\hline Unknown & $0.924(0.493-1.731)$ & 0.81 & $1.202(0.732-1.975)$ & 0.47 \\
\hline Surgeon (as random effect) ${ }^{*}$ & & 0.032 & & $0.26^{*}$ \\
\hline Recent surgery (2009-2010) & $1.127(0.705-1.800)$ & 0.48 & Removed from model & \\
\hline Ventricular catheter tip location & & 0.37 & Removed from model & \\
\hline Frontal horn & Referent & Referent & & \\
\hline Trigone & $1.227(0.782-1.925)$ & 0.37 & & \\
\hline Body & $1.287(0.904-1.834)$ & 0.16 & & \\
\hline 3rd ventricle & $1.274(0.391-4.148)$ & 0.69 & & \\
\hline Temporal horn & $1.343(0.393-4.588)$ & 0.64 & & \\
\hline Cistern & $2.058(0.466-9.099)$ & 0.34 & & \\
\hline Brain & $1.745(1.095-2.779)$ & 0.02 & & \\
\hline
\end{tabular}

\footnotetext{
* Surgeon was kept in the model as a random effect to control for within-surgeon clustering.
} 
TABLE 4. Baseline characteristics by entry site

\begin{tabular}{|c|c|c|c|}
\hline Variable & Anterior Entry Site & Posterior Entry Site & Significance \\
\hline No. of subjects & 299 & 552 & \\
\hline Mean age $\pm S D$, yrs & $1.76 \pm 3.64$ & $1.44 \pm 3.25$ & $0.011^{*}$ \\
\hline Categorical age & & & $0.02 \dagger$ \\
\hline$<1 \mathrm{mo}$ & $88(29.4 \%)$ & $189(34.2 \%)$ & \\
\hline 1 to $<6$ mos & $96(32.1 \%)$ & $193(35.0 \%)$ & \\
\hline 6 to $<12$ mos & $36(12.0 \%)$ & $59(10.7 \%)$ & \\
\hline 1 to $<10 \mathrm{yrs}$ & $60(20.1 \%)$ & $84(15.2 \%)$ & \\
\hline$\geq 10 \mathrm{yrs}$ & $19(6.4 \%)$ & $27(4.9 \%)$ & \\
\hline Female sex & $132(44.1 \%)$ & $238(43.1 \%)$ & 0.77 \\
\hline Etiology & & & 0.48 \\
\hline Aqueductal stenosis & $17(5.7 \%)$ & $44(8.0 \%)$ & \\
\hline Brain tumor & $24(8.0 \%)$ & $39(7.1 \%)$ & \\
\hline IVH of prematurity & $65(21.7 \%)$ & $138(25.0 \%)$ & \\
\hline Myelomeningocele & $73(24.4 \%)$ & $140(25.4 \%)$ & \\
\hline Head injury & $9(3.0 \%)$ & $10(1.8 \%)$ & \\
\hline CSF infection & $11(3.7 \%)$ & $25(4.5 \%)$ & \\
\hline 2 indicated & $15(5.0 \%)$ & $32(5.8 \%)$ & \\
\hline Other & $32(10.7 \%)$ & $56(10.1 \%)$ & \\
\hline Unknown & $52(17.4 \%)$ & $66(12.0 \%)$ & \\
\hline Missing data & $1(0.3 \%)$ & $2(0.4 \%)$ & \\
\hline Period of shunt insertion & & & $<0.001$ \\
\hline 1993-1998 & $224(74.9 \%)$ & $506(91.7 \%)$ & \\
\hline 2009-2010 & $75(25.1 \%)$ & $46(8.3 \%)$ & \\
\hline \multicolumn{4}{|l|}{ Surgeons $(n=60)$} \\
\hline No. in group & 37 & 52 & \\
\hline No. $w / \geq 10$ cases & 26 & 24 & \\
\hline Patients treated by surgeon performing $\geq 10$ cases $(\%)$ & 90.3 & 77.9 & $<0.001$ \\
\hline
\end{tabular}

rate of shunt obstruction between anterior and posterior shunts. The rate of infection, overdrainage, and failure due to loculations were similar between the 2 entry sites.

\section{Discussion}

This secondary analysis of 3 previous pediatric hydrocephalus studies was undertaken to determine the best target within the ventricle for the ventricular catheter tip when placing a first-time shunt; however, the study failed to identify a specific target. The analysis of the various catheter positions simply suggests that the most important factor for the catheter tip is that some portion of the tip is within the ventricle. Not surprisingly, if none of the catheter tip is in the ventricle, the outcome is poor. However, somewhat surprisingly, it does not seem to matter if a portion of the catheter tip is within the body, trigone, or frontal horn of the lateral ventricle; touches the wall; penetrates the ventricular wall; or crosses midline. Regarding the target, we can only conclude that shunts survive longer when some or all of the catheter tip is within the ventricle compared with when all of the catheter tip is not in ventricle (there were not enough cases of catheters in the temporal horn or third ventricle to be included in the analysis, so conclusions about catheters in these locations cannot be made).

The analysis, however, does indicate that the choice of entry site has a much more significant effect on determining shunt survival than the placement of the catheter tip. Stated another way, where the catheter enters the brain on its way to the ventricle is more important than where the catheter ends up within the ventricle. This does not mean that the target is not important (e.g., a catheter tip embedded in the brain from any entry site will fail), but it does suggest that the orientation of the catheter within the ventricle may play a significant role in reducing the rate of catheter obstruction. Catheters from an anterior approach enter the frontal horn or body of the ventricle through the roof and hang down into the ventricle like a chandelier; this may lead to less contact with the ventricular walls, floor, and choroid plexus and result in less obstruction and longer survival times. Catheters that enter the ventricle from a posterior approach come in through the walls of the ventricle and may be more likely to rest on the ventricular floor or choroid plexus, and this may result in earlier obstruction. 
TABLE 5. Association between ventricular catheter tip location and entry site*

\begin{tabular}{|c|c|c|c|}
\hline $\begin{array}{l}\text { Ventricular } \\
\text { Catheter Tip } \\
\text { Location }\end{array}$ & $\begin{array}{l}\text { Anterior Entry } \\
\quad(n=258)\end{array}$ & $\begin{array}{l}\text { Posterior Entry } \\
\qquad(\mathrm{n}=397)\end{array}$ & $p$ Value \\
\hline Frontal horn & 195 & 94 & \multirow{21}{*}{$<0.001 \dagger$} \\
\hline Row \% & $67.5 \%$ & $32.5 \%$ & \\
\hline Column \% & $75.6 \%$ & $23.7 \%$ & \\
\hline Body & 37 & 143 & \\
\hline Row \% & $20.6 \%$ & $79.4 \%$ & \\
\hline Column \% & $14.3 \%$ & $36.0 \%$ & \\
\hline Trigone & 1 & 106 & \\
\hline Row \% & $0.9 \%$ & $99.1 \%$ & \\
\hline Column \% & $0.4 \%$ & $26.7 \%$ & \\
\hline Temporal horn & 0 & 6 & \\
\hline Row \% & & $100 \%$ & \\
\hline Column \% & & $1.5 \%$ & \\
\hline 3rd ventricle & 7 & 2 & \\
\hline Row \% & $77.8 \%$ & $22.2 \%$ & \\
\hline Column \% & $2.7 \%$ & $0.5 \%$ & \\
\hline Cistern & 1 & 4 & \\
\hline Row \% & $20.0 \%$ & $80.0 \%$ & \\
\hline Column \% & $0.4 \%$ & $1.0 \%$ & \\
\hline Brain & 17 & 42 & \\
\hline Row \% & $28.8 \%$ & $71.2 \%$ & \\
\hline Column \% & $6.6 \%$ & $10.6 \%$ & \\
\hline
\end{tabular}

* Distributions shown in this table explain the confounding relationship between the 2 variables.

† Fisher's exact test using 100,000 Monte Carlo simulations.

\section{Study Limitations}

The timing of the postoperative scans in this study was not uniform, and this can affect the relationship of the catheter tip to various structures, especially as the ventricles decrease in size or the brain grows. For example, "surrounded by CSF" can become "touching ventricular wall" depending on the timing of the scan. "All holes in ventricle" can become "catheter too short" as the head grows. There is no reliable way to correct for this in the analysis.

These analyses are not the results of a randomized trial. None of the 3 studies used to create this cohort dictated the choice of catheter entry site. Surgeons chose the entry site in each subject based on factors that we cannot determine from the data set. This decision was made based on surgeon preference and was perhaps influenced by patient factors. It is very possible that an unknown confounder or confounders are responsible for the results seen in this analysis.

Our findings also only pertain to first-time shunt insertions, and may not apply to shunt revision surgery.

We also should interpret the results of this study with caution because most of the cases in the data set are from the 1990s, and the recent HCRN Registry data does suggest that shunt survival is better now than it was in the 1990s. ${ }^{6}$

Finally, the subjects in the data set from the SDT and ESIT have been analyzed many times in multiple ways, making it possible that the results produced here are due to chance alone.

\section{Previous Work Related to Entry Site}

Previous work looking at the effect of entry site on shunt survival comes from the late 1980s and early 1990s. In a retrospective analysis of 114 patients, Albright et al.

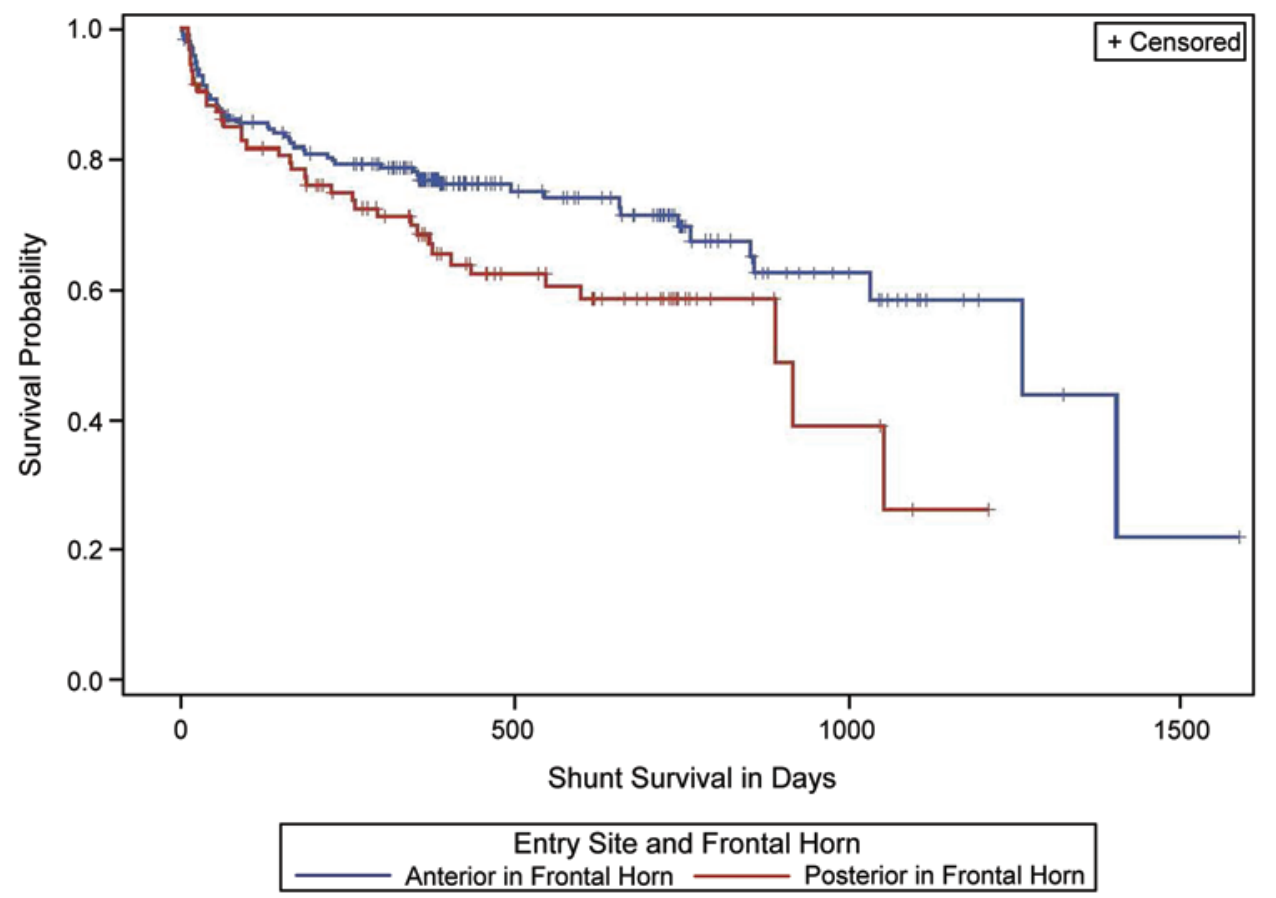

FIG. 4. Kaplan-Meier shunt survival curves for entry site with all catheter tips in the frontal horn. Log-rank $\chi^{2}=4.4450, p=0.035$. 
TABLE 6. Comparison of entry site by cause of shunt failure

\begin{tabular}{lccc}
\hline \multicolumn{1}{c}{ Outcome } & $\begin{array}{c}\text { Anterior Entry } \\
(\mathrm{n}=299)\end{array}$ & $\begin{array}{c}\text { Posterior Entry } \\
(\mathrm{n}=552)\end{array}$ & $\begin{array}{c}\mathrm{p} \\
\text { Value }\end{array}$ \\
\hline Obstruction & $18.7 \%$ & $33.0 \%$ & $<0.001$ \\
\hline Overdrainage & $2.7 \%$ & $3.4 \%$ & 0.54 \\
\hline Loculation & $2.3 \%$ & $0.9 \%$ & $0.125^{*}$ \\
\hline Infection & $10.0 \%$ & $9.2 \%$ & 0.71 \\
\hline $\begin{array}{l}\text { Never met criteria for shunt } \\
\text { failure during follow-up }\end{array}$ & $66.2 \%$ & $53.4 \%$ & \\
\hline
\end{tabular}

* Fisher's exact test.

found that anterior shunts lower the risk of shunt failure by approximately one-third. ${ }^{1}$ These results were controversial at the time and quickly led to a randomized controlled trial by Bierbrauer et al. ${ }^{3}$ The trial analyzed 121 pediatric patients randomized between anterior and posterior entry site and concluded that posterior entry sites were no worse than anterior entry sites. Shunt survival curves comparing the 2 groups did show a statistically significant improvement in survival for posterior shunts. The study protocol, however, may have allowed bias to significantly affect the study results. In particular, subjects were randomized based on the month of the year, so surgeons were aware of the treatment assignment prior to entering a subject into the trial; this can be a significant source of bias and is not true randomization. No steps were taken to minimize bias in the assessment of the primary outcome (criteria for shunt failure were not defined, and failure was determined by the operating surgeon). The methods for determining sample size and data analysis were not reported. Entry site locations were not specifically defined.

\section{Additional Study Is Necessary}

This analysis suggests that anterior entry site selection is a significant modifiable risk factor for shunt failure for patients receiving their first shunt. However, like all studies with this design, these results are best used to generate hypotheses and to support and plan more definitive prospective interventional studies. Based on this study, a randomized controlled trial has been planned and is currently recruiting patients within the HCRN (The CSF Shunt Entry Site Trial, clinicaltrials.gov: NCT02425761). A well-designed randomized controlled trial limits the effect of confounders and bias; it is the best methodology for comparing 2 treatments. The results of such a trial are necessary before treatment recommendations can be made regarding the best shunt entry site.

\section{Conclusions}

Using a large cohort of pediatric patients undergoing first-time shunt insertion, we failed to identify an ideal target within the ventricle for the shunt catheter tip. Unexpectedly, we found that entry site selection has a greater effect on shunt survival than ventricular catheter tip placement. Entry site may represent a modifiable risk factor for shunt failure, but more rigorous study is needed before a practice change can be recommended.

\section{Acknowledgments}

We would like to thank Kristine Eco, medical writer for the Department of Neurosurgery, Baylor College of Medicine, for her expert editorial assistance.

This study was funded by the Joint Section on Pediatric Neurological Surgery, American Association of Neurological Surgeons Research Support Award, 2010. The HCRN has been funded by National Institute of Neurological Disorders and Stroke (NINDS grant no. 1RC1NS068943-01), Patient-Centered Outcome Research Institute (PCORI award no. CER-1403-13857), The Gerber Foundation (reference no. 1692-3638), private philanthropy, and the Hydrocephalus Association. Dr. Simon was supported by Award K23NS062900 from the National Institute of Neurological Disorders And Stroke and Seattle Children's Center for Clinical and Translational Research, and CTSA Grant Number ULI RR025014 from the National Center for Research Resources, a component of the National Institutes of Health.

\section{References}

1. Albright AL, Haines SJ, Taylor FH: Function of parietal and frontal shunts in childhood hydrocephalus. J Neurosurg 69:883-886, 1988

2. Becker DP, Nulsen FE: Control of hydrocephalus by valveregulated venous shunt: avoidance of complications in prolonged shunt maintenance. J Neurosurg 28:215-226, 1968

3. Bierbrauer KS, Storrs BB, McLone DG, Tomita T, Dauser R: A prospective, randomized study of shunt function and infections as a function of shunt placement. Pediatr Neurosurg 16:287-291, 1990-1991

4. Drake JM, Kestle JR, Milner R, Cinalli G, Boop F, Piatt J Jr, et al: Randomized trial of cerebrospinal fluid shunt valve design in pediatric hydrocephalus. Neurosurgery 43:294-305, 1998

5. Kestle JR, Drake JM, Cochrane DD, Milner R, Walker ML, Abbott R III, et al: Lack of benefit of endoscopic ventriculoperitoneal shunt insertion: a multicenter randomized trial. J Neurosurg 98:284-290, 2003

6. Kulkarni AV, Riva-Cambrin J, Butler J, Browd SR, Drake JM, Holubkov R, et al: Outcomes of CSF shunting in children: comparison of Hydrocephalus Clinical Research Network cohort with historical controls: clinical article. J Neurosurg Pediatr 12:334-338, 2013

7. LaMorte WW, Sullivan L: Confounding and the Effect Measure Modification. Boston: Boston University School of Public Health, 2014 (http://sphweb.bumc.bu.edu/otit/MPHModules/BS/BS704-EP713 Confounding-EM/BS704-EP713 Confounding-EM print.html) (Accessed September 9, 2016)

8. Landis JR, Koch GG: The measurement of observer agreement for categorical data. Biometrics 33:159-174, 1977

9. Pang D, Grabb PA: Accurate placement of coronal ventricular catheter using stereotactic coordinate-guided free-hand passage. Technical note. J Neurosurg 80:750-755, 1994

10. Tuli S, O’Hayon B, Drake J, Clarke M, Kestle J: Change in ventricular size and effect of ventricular catheter placement in pediatric patients with shunted hydrocephalus. Neurosurgery 45:1329-1335, 1999

11. Whitehead WE, Riva-Cambrin J, Wellons JC III, Kulkarni AV, Holubkov R, Illner A, et al: No significant improvement in the rate of accurate ventricular catheter location using ultrasound-guided CSF shunt insertion: a prospective, controlled study by the Hydrocephalus Clinical Research Network. J Neurosurg Pediatr 12:565-574, 2013

\section{Disclosures}

The authors report the following. Dr. Limbrick receives sup- 
port for basic science research efforts from Medtronic, Inc., and Karl Storz, Inc., unrelated to the current study. Dr. Browd is cofounder and has equity and stock options in Aqueduct Neurosciences, Inc., Aqueduct Critical Care, Inc., and Navisonics, Inc., all of which are unrelated to the current study. None of the sponsors participated in design and conduct of this study; collection, management, analysis, and interpretation of the data; or preparation, review, or approval of this manuscript. Its contents are solely the responsibility of the authors and do not necessarily represent the official view of the sponsors.

\section{Author Contributions}

Conception and design: Whitehead, Riva-Cambrin, Kulkarni, Wellons, Rozzelle, Tamber, Limbrick, Browd, Naftel, Shannon, Simon, Holubkov, Cochrane, Drake, Luerssen, Oakes, Kestle. Acquisition of data: Whitehead, Illner, Kestle. Analysis and interpretation of data: Whitehead, Riva-Cambrin, Kulkarni, Wellons, Rozzelle, Tamber, Limbrick, Browd, Naftel, Shannon, Simon, Holubkov, Cochrane, Drake, Luerssen, Oakes, Kestle. Draft- ing the article: Whitehead, Holubkov, Illner, Kestle. Critically revising the article: all authors. Reviewed submitted version of manuscript: all authors. Approved the final version of the manuscript on behalf of all authors: Whitehead. Statistical analysis: Whitehead, Holubkov. Administrative/technical/material support: Whitehead. Study supervision: Whitehead.

\section{Supplemental Information}

\section{Previous Presentations}

Portions of this work were presented in abstract form at the American Association of Neurological Surgeons and Congress of Neurological Surgeons Joint Section Meeting on Pediatric Neurosurgery, St. Louis, Missouri, November 27-30, 2012.

\section{Correspondence}

William E. Whitehead, Texas Children's Hospital, 6701 Fannin St., CCC 1230.01, Houston, TX 77030.email: wewhiteh@ texaschildrenshospital.org. 